\title{
A randomised clinical trial comparing interferon- $\alpha$ and intravenous immunoglobulin in polyneuropathy associated with monoclonal IgM
}

Xavier Mariette, Claude Chastang, Jean-Pierre Louboutin, Jean-Marc Leger, Pierre Clavelou,Jean-Claude Brouet, for the IgM-associated Polyneuropathy Study Group*

Abstract

Objectives-The polyneuropathy associated with a monoclonal IgM directed to the myelin associated glycoprotein (MAG) is a specific entity with a putative causal link between the IgM and the neuropathy. The small benefit offered by alkylating agents or plasma exchanges in these patients justifies the search for alternative treatments.

Methods-A 12 month multicentre, prospective, randomised, open clinical trial was carried out comparing intravenous immunoglobulin (IVIg; 2g/kg and then 1 g/kg every three weeks) and recombinant interferon- $\alpha$ (IFN- $\alpha$; $3 \mathrm{MU} / \mathrm{m}^{2}$ subcutaneously three times weekly). The main end point was a clinical neuropathy disability score (CNDS) after six months of treatment. Twenty patients were enrolled; 10 were assigned to IVIg and 10 to IFN- $\alpha$.

Results-At six months, one out of 10 patients treated with IVIg had a CNDS improvement of more than $20 \%$ whereas eight out of 10 patients treated with IFN-a had such an improvement $(P=0.005)$. The mean CNDS worsened by 2.3 (SD 7.6) $(8 \%)$ in the IVIg group whereas it improved by 7.5 (SD 11.1$)(31 \%)$ in the IFN- $\alpha$ group $(P=0.02)$. This improvement persisted after 12 months and was mainly related to an improvement of the sensory component $(P=0.02)$ whereas the motor component was unchanged $(P=0.39)$. Electrophysiological data did not show improvement of motor nerve conduction velocities whereas sensory nerve conduction velocities improved in the upper limbs. A decrease in the level of the monoclonal IgM was seen in two patients treated with IFN-a. At the end of the treatment, antibody activity to MAG was still detected in the serum of all patients. Conclusion-IVIg, as used in this study, did not improve patients with polyneuropathy and monoclonal IgM. By contrast, although its mechanism of action remains to be fully elucided, IFN- $\alpha$ was effective in eight out of 10 patients at six months.

(F Neurol Neurosurg Psychiatry 1997;63:28-34)

Keywords: monoclonal IgM gammapathy; antimyelin associated glycoprotein antibody; polyneuropathy; interferon- $\alpha$; intravenous immunoglobulin
A peripheral neuropathy may be associated with a serum monoclonal $\operatorname{IgM}$ in the presence or absence of an overt lymphoid proliferative disease such as Waldenström's macroglobulinaemia. ${ }^{1-3}$ A causal link between the monoclonal IgM and the development of neuropathy is suggested by (1) the specificity of most of these IgMs for the myelin associated glycoprotein (MAG), ${ }^{45}$ peripheral nerve glycolipids, ${ }^{6-8}$ and low molecular weight polypeptides ${ }^{9}$; (2) the detection by immunofluorescence of $\operatorname{IgM}$ and complement deposits on the myelin sheaths of patients' nerve biopsies $^{210}{ }^{11}$; (3) the induction, in animal models, of the neuropathological process through the transfer of the anti-MAG $\operatorname{IgM}^{12} 13$ or by the intraneural injection of the $\operatorname{IgM}$ in peripheral nerves. ${ }^{14}$ Because IgM associated neuropathy usually has a progressive course and can be responsible for severe disabling sensory and motor symptoms, effective therapy is necessary. Chlorambucil is given in chronic B cell malignancies such as chronic lymphocytic leukaemia and Waldenström's macroglobulinaemia and could therefore be active on anti-MAG secreting $B$ cells, even in the absence of a detectable lymphoid proliferation. ${ }^{15}$ However, in a previous study of 44 patients with IgM associated neuropathy, treatment with chlorambucil was unsucessful in two thirds of the patients and yielded only a slight improvement in the others. ${ }^{16}$ No benefit from plasma exchange was found in this study. Likewise, a double blind study of plasma exchange in patients with monoclonal $\operatorname{IgM}$ neuropathy failed to show any benefit. ${ }^{17}$ Therefore, a more effective therapeutic approach is warranted. Two potential useful treatments need to be tested: intravenous immunoglobulins (IVIg), which have been used with some improvement in a few patients, ${ }^{18}{ }^{19}$ and interferon- $\alpha$ (IFN- $\alpha)$ which induces remission in Waldenström's macroglobulinaemia, ${ }^{20}$ as well as in monoclonal gammapathies of undetermined significance associated with mixed cryoglobulinaemia $^{21}$ or cold agglutinins. ${ }^{22}$ Moreover, IFN- $\alpha$ may inhibit the spontaneous in vitro differentiation of purified B lymphocytes to plasma cells which was found in monoclonal gammapathies of undetermined significance. ${ }^{23}$ Instead of conducting two independent phase II trials with each of these two treatments, we designed a multicentre, prospective, randomised, open clinical trial 
assessing IVIg and IFN- $\alpha$. Due to its disappointing results, ${ }^{16}$ chlorambucil was not used as a reference. As assessment of these treatments in this chronic disease requires long term therapy, it was considered that a placebo group would be unethical.

\section{Methods}

PATIENTS AND CRITERIA FOR INCLUSION

Patients included in this study were recruited from five French departments of neurology and one department of immunohaematology. They had to fulfill the following criteria : (1) stable or progressive neuropathy for at least three months; (2) presence of a serum monoclonal IgM with anti-MAG antibody activity as detected by immunoblotting on delipidated human myelin ${ }^{7}$; (3) a clinical neuropathy disability score (CNDS) $>10$ (see below); (4) exclusion of other causes of peripheral neuropathy, especially diabetes, alcohol misuse, cryoglobulinaemia, and amyloidosis; (5) absence of treatment in the past three months.

\section{STUDY DESIGN AND TREATMENT}

The study was designed to be a multicentre, prospective, randomised, open clinical trial comparing two treatments. The protocol was approved by the Hôpital Saint-Louis ethics committee. After providing written informed consent, patients underwent stratified randomisation according to the existence of a previous treatment, through a blind telephone assignment procedure. The patients were randomly assigned to receive either IVIg or IFN- $\alpha$. IVIg (Laboratoire Français du Fractionnement et des Biotechnologies) was given at $500 \mathrm{mg} / \mathrm{kg} /$ day for the first four days followed by $500 \mathrm{mg} / \mathrm{kg} /$ day for two days every three weeks for a six month period and then, if improvement was found (more than 20\% improvement in the clinical neuropathy disability score (CNDS)), every six weeks for the next six months. Recombinant IFN- $\alpha$ (Roferon, Roche) was administered subcutaneously at 3 $\mathrm{MU} / \mathrm{m}^{2}$ three times a week for six months and, if improvement occurred, at $3 \mathrm{MU} / \mathrm{m}^{2}$ twice a week for the next six months. In cases of worsening of the neuropathy before the sixth month (more than 20\% worsening of the CNDS) or of absence of improvement at six months, the patients were switched to the other treatment.

EVALUATION OF NEUROPATHY

The clinical neuropathy disability score (CNDS) (see appendix 2) resulted from a slightly modified score described elsewhere. ${ }^{24} 25$ Briefly, selected items from the neurological evaluation were scored and summed. The function of 14 muscles $(\times 2)$ was scored as 0 if normal and 1 if abnormal; sensation (touchpressure, pin prick, warm-cold, joint motion, vibration) was scored in the same way; pain, paraesthesia and dysaesthesia were scored as 0 if absent and 1 if present; six muscle stretch reflexes $(\times 2)$ were scored as 0 if present and 1 if absent. Scores could range from 0 to 93, summing 0 to 28 points for the motor component, 0 to 12 for the reflexes component, and 0 to 53 points for the sensory component. In addition, the patient was asked to rate the change in five symptoms : paraesthesia, dysaesthesia, ability to feel the floor, tightness, and walking in major improvement $(-2)$, slight improvement $(-1)$, stability (0), slight worsening $(+1)$, major worsening $(+2)$. This score termed "subjective assessment" ranged from -10 to +10 and was added to the previous one in follow up examinations. The examinations were performed by the same physician for each patient.

\section{ELECTRODIAGNOSTIC STUDIES}

Electrodiagnostic studies were performed at baseline and after six and 12 months of treatment with a Viking Nicolet electromyograph. Needle EMG examination was performed in all patients. The incidence of spontaneous activity at rest (fibrillation potentials and positive sharp waves) was recorded. The size of motor unit potentials and the pattern of recruitment during maximal effort were also analysed. Motor nerve conduction studies were performed with supramaximal percutaneous nerve stimulation, whereas compound muscle action potentials (CMAPs) were recorded with surface electrodes. Median, ulnar, and peroneal nerves were examined on both sides. The median nerve was stimulated at the wrist and the elbow. The ulnar nerve was stimulated at the wrist, below and above the elbow. The peroneal nerve was stimulated at the ankle, below and above the fibular head. During all nerve conduction studies, skin temperature was maintained at $36^{\circ} \mathrm{C}$. Distal latencies, conduction velocity, and evoked motor response amplitudes (baseline to negative peak), were measured. Sensory nerve conduction and amplitude were measured in the median, ulnar, superficial peroneal, and sural nerves with surface recording and stimulating electrodes. The nerves were stimulated by orthodromic techniques in the upper limbs and antidromic techniques in the lower limbs. Amplitudes of the sensory nerve action potentials (SNAPs) were measured peak to peak.

\section{EFFICACY CRITERIA}

The main end point was defined by the change in the CNDS between the randomisation and the sixth month of therapy or the time of withdrawal of treatment if the treatment had been modified or stopped before the sixth month. The number of patients in each group who experienced an improvement of the CNDS of more than $20 \%$ was determined. Other criteria were (1) the change in the CNDS between the randomisation and the 12th month of therapy; (2) the change in electrophysiological data; (3) the change in the level of the monoclonal component; and (4) the change in the serum anti-MAG antibody activity.

\section{SAMPLE SIZE AND STATISTICAL ANALYSIS}

Estimation of sample size was based on the main criterion, using a two sample $t$ test. We were expecting a difference between treatment groups of 10 with an SD of 10, using the estimates derived from a previous trial. ${ }^{16}$ Specifying a type I error of 0.05 and a power of 0.90 , a 
Table 1 Baseline characteristics according to treatment

\begin{tabular}{lll}
\hline & $I V I g(n=10)$ & $I F N-a(n=10)$ \\
\hline Age $(\mathrm{y})$ & $66(10)(52-85)$ & $67(5)(60-76)$ \\
Sex $(\mathrm{M} / \mathrm{F})$ & $7 / 3$ & $9 / 1$ \\
Patients never previously treated & 6 & 6 \\
Duration of neuropathy (y) & $4.0(5.3)(0.4-17.8)$ & $3.1(1.8)(0.3-6.1)$ \\
Detection of monoclonal gammapathy (y) & $2.5(5.1)(0.1-16.8)$ & $1.6(2.1)(0.1-6.1)$ \\
Patients with bone marrow lymphoid infiltrate & 3 & 3 \\
Clinical score & $28.7(11.5)(10-48)$ & $24.4(11.3)(12-49)$
\end{tabular}

Values are means (SD) (range).

Table 2 Clinical evolution according to treatment

\begin{tabular}{lllll}
\hline Clinical score & Time (months) & IVIg $(n=10)$ & IFN- $a(n=10)$ & P value (Kruskal-Wallis) \\
\hline Global score & 0 & $28.7(11.5)$ & $24.4(11.3)$ & \\
& 6 & $31.0(11.3)$ & $16.9(13.3)$ & 0.02 \\
Motor score & $6-0$ & $2.3(7.6)$ & $-7.5(11.1)$ & 0.02 \\
& 0 & $3.5(3.3)$ & $2.9(5.5)$ & \\
Sensory score & 6 & $3.4(3.1)$ & $2.2(4.4)$ & 0.09 \\
& $6-0$ & $-0.1(1.4)$ & $-0.7(1.9)$ & 0.39 \\
Reflex score & 0 & $17.2(7.2)$ & $16.0(5.7)$ & \\
& 6 & $17.8(6.4)$ & $11.6(5.0)$ & 0.04 \\
& 6 & $0.6(4.5)$ & $-4.4(3.8)$ & 0.02 \\
Subjective & 6 & $8.0(4.0)$ & $5.5(3.9)$ & \\
assessment & $6-0$ & $9.6(4.1)$ & $6.0(4.9)$ & 0.14 \\
& $6-0$ & $1.6(2.3)$ & $0.5(4.1)$ & 0.10 \\
Val & $6.2(1.0)$ & $-2.9(3.2)$ & 0.01 \\
& & $0.2(1.0)$ & $-2.9(3.2)$ & 0.01 \\
\hline
\end{tabular}

Values are means (SD). a strong correlation between baseline CNDS and duration of disease $(r=0.62, \mathrm{P}=0.004$ by Spearman's test) and a trend for a relation between baseline CNDS and existence of a previous treatment $(\mathrm{P}=0.10$ by Kruskal-Wallis test).

In the IVIg group, four patients withdrew early from therapy; one because of toxicity (he developed a self limited erythroderma five days after the first course of IVIg), one for personal reason after one course of IVIg, and two after three and five courses of IVIg respectively for intercurrent diseases (acute decompensation of chronic bronchitis and traumatic fractures). None of these patients improved before they stopped IVIg. These patients were analysed in the IVIg group according to the intention to treat principle. One other patient of the IVIg group switched to the IFN- $\alpha$ group after four months of IVIg because of progression of the neuropathy. In the IFN- $\alpha$ group, no patients withdrew from therapy before the sixth month but the dosage of IFN- $\alpha$ was tapered to 2 $\mathrm{MU} / \mathrm{m}^{2}$ because of systemic adverse effects in three patients. No haematological toxicity was found in the IFN- $\alpha$ group. Flu-like symptoms occurred at the beginning of the treatment in all 10 patients treated with IFN- $\alpha$ but persisted in only three of them leading to tapering of the dosage to $2 \mathrm{MU} / \mathrm{m}^{2}$. There were no local adverse effects.

After six months of treatment, one out of 10 patients treated with IVIg had a decrease- that is, an improvement in CNDS - of more than $20 \%$ whereas eight out of 10 patients treated with IFN- $\alpha$ had such an improvement $(\mathrm{P}=0.005$ by Fisher's test). Table 2 presents the detailed results. The mean CNDS decreased (improved) by 7.5 (SD 11.1) (31\%) in the IFN- $\alpha$ group whereas it increased (worsened) by 2.3 (SD 7.6) (8\%) in the IVIg group ( $\mathrm{P}=0.02$ by Kruskal-Wallis test). The improvement in the IFN- $\alpha$ group was mainly related to an improvement of the sensory component of the CNDS $(\mathrm{P}=0.02$ by Kruskal-Wallis test) whereas the motor component of the CNDS was unchanged $(\mathrm{P}=0.39$ by Kruskal-Wallis test). The adjusted comparison for the three selected baseline variables (baseline CNDS, previous treatment, disease duration) also showed the benefit of IFN- $\alpha \quad(P=0.001)$. Among the nine patients treated unsuccessfully with IVIg, four stopped the protocol, three for intercurrent events (see above) and one for progression to overt lymphoma, and five were switched to IFN- $\alpha$. One of these five patients had an improvement of more than $20 \%$ with IFN- $\alpha$. The two patients of the IFN- $\alpha$ group who switched to IVIg had no improvement of the CNDS. The only patient who improved transiently with IVIg was refractory to chlorambucil. The four patients refractory to chlorambucil in the IFN- $\alpha$ group improved with IFN- $\alpha$ at six months but one of them returned to baseline score at 12 months.

The difference between the two groups persisted after 12 months. The only patient who improved with IVIg at six months returned to baseline score at 12 months. Among the eight patients who improved with IFN- $\alpha$ at six 
Table 3 Electrophysiological data according to treatment

\begin{tabular}{lllll}
\hline & $\begin{array}{l}\text { Time } \\
\text { (months) }\end{array}$ & $\begin{array}{l}\text { IVIg } \\
(n=8)\end{array}$ & $\begin{array}{l}I F N-a \\
(n=7)\end{array}$ & $\begin{array}{l}\text { Pvalue } \\
\text { (Kruskal-Wallis) }\end{array}$ \\
\hline Patients with absence of peroneal & 0 & 5 & 3 & \\
CAMP (n) & 6 & 4 & 3 & \\
Patients with absence of ulnar & 0 & 1 & 1 & \\
CAMP (n) & 6 & 1 & 1 & \\
Mean ulnar MNCV (m/s) & 0 & 32.1 & $33.1(15.0)$ & \\
& & $(18.4)$ & & \\
& 6 & 32.2 & $33.3(15.1)$ & 0.94 \\
Mean ulnar DL (ms) & 0 & $(16.9)$ & & \\
& 6 & $8.8(7.3)$ & $5.4(3.0)$ & \\
Patients with absence of sural & 0 & $7.4(5.9)$ & $6.6(2.4)$ & 0.73 \\
SNAP (n) & 6 & 5 & 5 & \\
Patients with absence of median & 0 & 7 & 5 & \\
SNAP (n) & 6 & 4 & 5 & \\
& 7 & & 2 & \\
\hline
\end{tabular}

Values in parentheses are SD.

CAMP $=$ Compound muscle action potential, $\mathrm{MNCV}=$ motor nerve conduction velocity, $\mathrm{DL}=$ distal latency, SNAP = sensory nerve action potential.

months, one worsened returning to his initial score, one was stable with a $75 \%$ decrease in the CNDS, and six experienced a sustained improvement (five of these six patients had a decrease of CNDS of more than $50 \%$ ). These six patients were willing to continue IFN- $\alpha$ treatment after the planned duration of the protocol. Four patients are still being treated with IFN- $\alpha$ at 2 million $\mathrm{U} / \mathrm{m}^{2}$ twice a week with $16,16,23$, and 40 months of follow up. The two other patients were treated for 18 and 40 months and remained stable 28 and five months respectively after IFN- $\alpha$ was disrupted.

Electrophysiological data were available in 15 patients (eight in the IVIg group, seven in the IFN- $\alpha$ group; table 3 ). These 15 patients had the same clinical evolution as the whole group (data not shown). At onset, CMAP was absent in the peroneal nerve in five patients in the IVIg group and in three patients in the IFN- $\alpha$ group and remained undetectable under treatment. The mean value of ulnar motor-nerve conduction velocities and distal latencies were not different between the two groups at six months. SNAPs of the sural nerves were not obtained in five patients in the IVIg group and in six patients in the IFN- $\alpha$ group at entry, and did not improve in the two groups. However, SNAPs of the median nerve, which was absent in four patients in the IVIg group and in five patients in the IFN- $\alpha$ group at baseline, was not obtained in seven patients in the IVIg group at six months and in only two patients in the IFN- $\alpha$ group at six months. Due to the large number of patients with no SNAP at baseline in the two groups, it was impossible to compare the evolution of sensory nerve conduction velocities (SNCVs) and amplitudes in the two groups. Nevertheless, the three patients in the IFN- $\alpha$ group without any median SNAP at baseline who recovered SNAPs after six months of IFN- $\alpha$ therapy had SNCVs of the median nerve of 29,33 , and $28 \mathrm{~m} / \mathrm{s}$ with amplitudes of $3.9,2.4$, and $3.0 \mathrm{mV}$ respectively.

At the end of the treatment, the antibody activity to MAG and the monoclonal IgM were detected in the serum of all of the patients. In two patients who improved under IFN- $\alpha$, the monoclonal component decreased by more than $50 \%$. In the other patients, no significant decrease in IgM was noted.

\section{Discussion}

The peripheral neuropathy associated with a monoclonal anti-MAG IgM is considered to be specific. $^{2-427}$ The clinical features are different from those found with monoclonal IgG or IgA, with more sensory loss and ataxia. A causal link between the monoclonal IgM and the development of neuropathy is suggested by the antibody activity of the IgM to nerve polypeptides or glycolipids, ${ }^{4-9}$ the detection of IgM deposits on the myelin sheaths of nerve biopsies from patients, ${ }^{210} 11$ and the induction of the neuropathological process through the transfer of the anti-MAG IgM in animal models. ${ }^{12}{ }^{13}$ The low rate $(30 \%)$ of clinical improvement with chlorambucil or plasma exchange in such patients ${ }^{16}{ }^{17}$ needs the development of new therapeutic strategies. A double blind double dummy trial could not be conducted because of the duration (one year) and the mode of administration of the treatment. The clinical score used in the present study was correlated with known predictive factors of the disease (duration of the neuropathy and need of a previous treatment) and therefore seems to be a satisfactory criterion for the evaluation of the neuropathy under treatment. The first interim analysis disclosed a benefit of IFN- $\alpha(\mathrm{P}=0.02$ by Kruskal-Wallis test) leading to no more inclusion of patients according to the rule defined in the protocol. Likewise, the adjusted comparison, which takes into account the baseline imbalances and the prognostic variables and allows for a better statistical power, rejected the null hypothesis with low significance levels $(\mathrm{P}=0.001$ at six months $)$ and strengthened the conclusion of a higher efficacy of IFN- $\alpha$ than IVIg. Treatment with IVIg has been found to be effective in several autoimmune diseases such as autoimmune thrombopenic purpura, polymyositis, and $\mathrm{Ka}-$ wasaki disease through a multiple potential mechanism (reviewed in Kazatchkine et $a l^{28}$ ). The use of IVIg has been proposed for the treatment of peripheral neuropathies suspected to be immune mediated such as Guillain-Barré syndrome, ${ }^{29}$ chronic inflammatory demyelinating polyneuropathy, ${ }^{30}$ and multifocal motor neuropathy. ${ }^{31}$ Two open trials tested IVIg in the treatment of peripheral neuropathy associated with monoclonal IgM gammapathy; Cook et al reported two patients who had clinical improvement after IVIg therapy ${ }^{18}$; a slight clinical improvement (grade 1 decrease of the Prineas score) was also found by Léger et al in six of 13 patients treated with IVIg ${ }^{19}$; however, in this study, most of the patients worsened after several months despite further treatment with IVIg. In our study, a clinical improvement with IVIg was found in only one patient at six months which disappeared at 12 months. The treatment was also unsuccessful in two patients of the IFN- $\alpha$ group who switched to IVIg. However, only six of the 10 patients in the IVIg group completed six months of therapy with IVIg. Indeed, four patients dropped out of 
treatment early because of intolerance (one patient), personal reasons (one patient), or intercurrent diseases (two patients). Moreover, the clinical score at baseline was higher in the IVIg group than in the IFN- $\alpha$ group (28.7 (SD 11.5) v 24.4 (SD 11.3)); and duration of neuropathy, usually associated with less reversible neuropathy, was longer (4 (SD 5.3) v 3.1 (SD 1.8)) years. IFN- $\alpha$ produced a significant clinical improvement in eight out of 10 patients at six months and in seven out of 10 patients at 12 months, six of these patients having a decrease of the global CNDS of more than $50 \%$. Four of these patients are still being treated with IFN- $\alpha$ and two have stable disease 28 and five months after stopping IFN- $\alpha$. Haematological and systemic tolerance of IFN- $\alpha$ were acceptable. Electrophysiological data did not show improvement of motor nerve conduction velocities. Although sensory nerve conduction velocities were not modified in the lower limbs, they significantly improved together with the potential amplitude in the upper limbs, which were less damaged at the onset. An electrophysiological improvement is likely to be detectable only if nerve demyelination is not too severe. As peripheral axonal neuropathy has been attributed to IFN- $\alpha$, although very rarely, ${ }^{32}$ the patients were followed up very carefully, but none of them experienced early worsening of their neuropathy. The mechanism of action of IFN- $\alpha$ is unclear. It induces a decrease in serum monoclonal $\operatorname{IgM}$ in almost half of patients with Waldenström's macroglobulinaemia ${ }^{20}$ but also in IgM monoclonal gammapathies of undetermined significance such as cold agglutinins. ${ }^{22}$ On the other hand, IFN- $\alpha$ is also effective in mixed cryoglobulinaemia associated with hepatitis C viral infections, probably because of its action on the replication of the virus. ${ }^{33}$ In this study, a decrease in the level of the monoclonal IgM was found in only two patients although the neuropathy improved in eight of 10 patients. The possibility that IFN- $\alpha$ led to an increase in polyclonal IgM antibodies which could have masked its effect on the monoclonal $\operatorname{IgM}$ is unlikely because IgM was still detected by immunofixation and anti-MAG antibody activity was still present in the serum of all patients after treatment. Therefore, the mechanism of action which has been anticipated seems to play a minor part, if any, in the improvement of the neuropathy. Unexpectedly, this holds true also for patients who improved with chemotherapy. ${ }^{16}$ Of note, IFN- $\alpha$ has been found to be active in an autoantibody mediated neurological disease in mice-experimental autoimmune myasthena gravis-without decreasing the amount of pathogenic antibodies to the acetylcholine receptor. ${ }^{34}$ Therefore, the potential beneficial role of IFN- $\alpha$ in some autoimmune diseases may be linked to mechanisms of action other than the decrease of production of autoantibodies. IFN- $\alpha$ has multiple functional effects on various cell types which might offer some clues. ${ }^{35}$ It may decrease the level of mRNA for proinflammatory cytokines such as tumour necrosis factor TNF- $\alpha$ and the interleukins IL1 and IL6, downregulate MHC class II expression, upregulate the immunosuppressive cytokine TGF- $\beta$, and upregulate the expression of adhesion molecules. This last mechanism could be relevant in anti-MAG associated neuropathies. It is conceivable that IFN- $\alpha$ decreases the permeability of the bloodperipheral nerve barrier-for instance, by modulating the expression of adhesion molecules ${ }^{36}$ - which could result in a more limited acces of anti-MAG IgM to the peripheral nervous system. In this setting, it is of interest that endothelial cells in the bovine nervous system express the glycolipid sulphoglucuronosyl paragloboside, which is a target of anti-MAG antibodies, and that human monoclonal antiMAG IgM antibodies increase the leakage of ${ }^{14} \mathrm{C}$-inulin and ${ }^{125} \mathrm{I}-\mathrm{IgM}$ through brain microvascular endothelial cells monolayers. ${ }^{37}$

In conclusion, IVIg, as used in this study, did not improve patients with polyneuropathy associated with monoclonal anti-MAG IgM. By contrast, although its mechanism of action remains to be fully elucidated, IFN- $\alpha$ was effective in eight out of 10 patients at six months and in seven out of 10 patients at 12 months. Evaluation of sustained benefit in this chronic disease requires long term follow up.

This work was supported by a grant from The Délégation de la Recherche Clinique (Assistance Publique-Hôpitaux de Paris).

1 Latov N. Waldenstrom's macroglobulinemia and nonmalignant IgM monoclonal gammapathies. In: Kelly JJ, Kyle RA, Latov N, eds. Polyneuropathies associated with plasma cell dyscrasia. Boston: Martinus Nijhoff, 1987:51-

2 Smith IS, Kahn SN, Lacey BW, et al. Chronic demyelinating neuropathy associated with benign IgM paraproteinemia. Brain 1983;106:169-95.

3 Dellagi K, Dupouey P, Brouet JC, et al. Waldenstrom's macoglobulinemia and peripheral neuropathy: a clinical and immunologic study of 25 patients. Blood 1983;62:280-5.

4 Latov N, Sherman WH, Nemni R, et al. Plasma-cell dyscrasia and peripheral neuropathy with a monoclonal antibody to peripheral-nerve myelin. N Engl f Med 1980;303:61821 .

5 Braun PE, Frail DE, Latov N. Myelin-associated glycoprotein is the antigen for a monoclonal IgM in polyneuropathy. 7 Neurochem 1982;39:1261-5.

6 Chou DKH, Ilyas AA, Evans JE, et al. Structure of a glycolipid reacting with monoclonal IgM in neuropathy and with pid reacting with monoclonal IgM in neuropathy and

7 Hauttecœur B, Schmitt C, Dubois C, et al. Reactivity of human monoclonal IgM with nerve glycosphingolipids. Clin Exp Immunol 1990;80:181-5.

8 Jauberteau MO, Henin D, Bouche P, et al. Etude des anticorps anti-glycolipides au cours des dysglobulinémies monoclonales à IgM associées à une neuropathie périphérique. Rev Neurol 1988;144:474-80.

9 Bollensen E, Steck A, Schachner M. Reactivity of the peripheral myelin glycoprotein $\mathrm{PO}$ in serum from patients with monoclonal IgM gammapathy and polyneuropathy. Neurology 1988;38:1266-70.

10 Mendell JR, Sahenk Z, Whitaker JN, et al. Polyneuropathy and IgM monoclonal gammopathy: studies on the pathogenic role of anti-myelin-associated glycoprotein antibody. Ann Neurol 1985;17:243-54.

11 Monaco S, Bonetti B, Ferrari S, et al. Complementmediated demyelination in patients with IgM monoclonal gammopathy and polyneuropathy. $N$ Engl f Med 1990;322: gammopa

12 Tatum AH. Experimental paraprotein neuropathy, demyelination by passive transfer of human IgM anti-myelinassociated glycoprotein. Ann Neurol 1993;33:502-6.

13 Dancea S, Dellagi K, Renaud F, et al. Effect of passive transfer of human anti-myelin-associated glycoprotein IgM in marmoset. Autoimmunity 1989;3:29-37.

14 Hays AP, Latov N, Takatsu M, Sherman WH. Experimental demyelination of nerve induced by serum of patients with neuropathy and an anti-MAG IgM M protein. Neurology 1987;37:242-56.

15 Nobile-Orazio E, Baldini L, Barbieri S, et al. Treatment of patients with neuropathy and anti-MAG IgM M-proteins. Ann Neurol 1988;24:93-7.

16 Oksenhendler E, Chevret S, Léger JM, et al for the IgM-associated Polyneuropathy Study group. Plasma exchange and chlorambucil in polyneuropathy associated with monoclonal IgM gammopathy. $f$ Neurol Neurosurg with monoclonal IgM gam
Psychiatry 1995;59:243-7. 
17 Dyck PJ, Low PA, Windebank AJ, et al. Plasma exchange in polyneuropathy associated with monoclonal gammopathy of undetern

18 Cook D, Dalakas M, Galdi A, et al. High-dose intravenous immunoglobulin in the treatment of demyelinating neuropathy associated with monoclonal gammopathy. Neurology 1990;40:212-4.

19 Léger JM, Ben Younes-Chennoufi A, Chassande B, et al. Treatment with human immunoglobulin of multifocal motor neuropathy and of polyneuropathy associated with monoclonal gammopathy. 7 Neurol Neurosurg Psychiatry 1995;57(suppl):46-9.

20 Rotoli B, De Renzo A, Frigeri F, et al. A phase II trial on $\alpha$-interferon $(\alpha \mathrm{IFN})$ effect in patients with monoclonal IgM gammopathy. Leuk Lymphoma 1994;13:463-9.

21 Bonomo L, Casato M, Afeltra A, Caccavo D. Treatment of idiopathic mixed cryoglobulinemia with $\alpha$ interferon. $A m \mathcal{F}$ Med 1987;83:726-30

22 Fest $\mathrm{T}$, de Wazières $\mathrm{B}$, Lamy B, et al. Successful response to $\alpha$-interferon $2 b$ in a refractory IgM autoagglutininmediated hemolytic anemia. Ann Hematol 1994;69:147-9.

23 Levy Y, Fermand JP, Navarro S, et al. Interleukin 6 dependence of spontaneous in vitro differentiation of B cells from patients with IgM gammapathy. Proc Natl Acad Sci USA 1990;87:3309-13.

24 Dyck PJ, Sherman WR, Hallcher LM, et al. Human diabetic endoneurial sorbital, fructose, and myo-inositol related to sural nerve morphometry. Ann Neurol 1980;8:590-6.

25 Dyck PJ, Daube J, O'Brien P, et al. Plasma exchange in chronic inflammatory demyelinating polyneuropathy. $N$ Engl f Med 1986;314:461-5.

26 Pocock SJ. Group sequencial methods in the design and analysis of clinical trials. Biometrika 1977;64:191-9.

27 Steck AJ, Murray N, Dellagi K, et al. Peripheral neuropathy associated with monoclonal IgM autoantibody. Amn Neurol $1987 ; 22: 764-7$
28 Kazatchkine MD, Dietrich G, Hurez V, et al. V regionmediated selection of autoreactive repertoires by
intravenous immunogloublin (iv Ig). Immunological Rev intravenous im

29 Van der Meché FGA, Schmitz PIM, and the Dutch Guillain-Barré Study Group. A randomized trial comparing intravenous immune globulin and plasma exchange in Guillain-Barré syndrome. N Engl f Med 1992;326:1123-9.

30 Van Doorn PA, Brand A, Strengers PFW, Meulstee J, Vermeulen M. High-dose intravenous immunoglobulin treatment in chronic inflammatory demyelinating polyneuropathy: a double-blind, placebo-controlled, crossover study. Neurology 1990;40:209-12.

31 Chaudhry V, Corse AM, Cornblath DR, et al. Multifocal motor neuropathy : response to human immune globulin. Ann Neurol 1993;33:2437-42.

32 Gastineau DA, Habermann TM, Hermann RC. Severe neuropathy associated with low-dose recombinant

33 Misiani R, Bellavita P, Fenili D, et al. Interferon $\alpha-2$ a therapy in cryoglobulinemia associated with hepatitis $\mathrm{C}$ virus. $N$ Engl fMed 1994:330:751-6.

34 Shenoy M, Baron S, Wu B, Goluszko E, Christadoss P. IFN-a treatment suppresses the development of experimental autoimmune myasthenia gravis. Immunol 1995;154: 6203-8.

35 Gutterman JU. Cytokine therapeutics: lessons from interferon $\alpha$. Proc Natl Acad Sci USA 1994;91:1198-205.

36 Upadhyaya G, Guba SC, Sih SA, et al. Interferon- $\alpha$ restores the deficient expression of the cytoadhesion molecule lymphocyte function antigen-3 by chronic myelogenous leukemia progenitor cells. F Clin Invest 1991;88:2131-6.

37 Kanda T, Yoshino $H$, Ariga T, Yamawaki M, Yu RK. Glycosphingolipid antigens in cultured microvascular bovine brain endothelial cells: sulfoglucuronosyl paragloboside as a target of monoclonal IgM in demyelinative neuropathy. Cell Biol 1994;126:235-46.

\section{Appendix 1: The IgM associated Polyneuropathy Study Group}

Claudie Autran, Service d'Hématologie, Centre hospitalier Morvan, Brest; Djaouida Bengoufa, Laboratoire d'Immunologie, Hôpital Saint-Louis, Paris; Pierre Bouche et Jean-Marc Léger, Clinique des Maladies du Système Nerveux, Hôpital de la Salpêtrière, Paris; Jean-Claude Brouet, Jean-Paul Fermand, Xavier Mariette and Eric Oksenhendler, Service d'Immuno-Hématologie, Hôpital Saint-Louis, Paris; Pierre Clavelou and Renato Colamarino, Service de Neurologie, Hôpital Fontmaure, Chamalières; Claude Chastang, Département de Biostatistique et Informatique Médicales, Hôpital Saint-Louis, Paris; Marie-José Rapp Service d'Hématologie, Centre hospitalier Hotel-Dieu, Nantes; Claire Kulekci-Sauvage, Service d'Hématologie, Hôpital Cochin, Paris; Jean-Pierre Louboutin and Bruno Elie, Service de Neurologie, Hôpital Laennec, Nantes; Isabelle Pénisson, Service de Neurologie, Centre hospitalier d'Angers; Jean-Paul Piadé, Laboratoire d'Electromyographie, Hôpital Lariboisière, Paris.

Appendix 2: Clinical neurological disability score ( $\mathrm{Y}=$ yes, $\mathrm{N}=$ no)

\begin{tabular}{|c|c|c|c|c|}
\hline & \multicolumn{2}{|l|}{ Right } & \multicolumn{2}{|c|}{ Left } \\
\hline \multicolumn{5}{|l|}{ I Muscle weakness } \\
\hline \multicolumn{5}{|l|}{ Upper limbs: } \\
\hline Holding or keeping a pencil (between thumb and index) & $\mathrm{Y}$ & $\mathrm{N}$ & $\mathrm{Y}$ & $\mathrm{N}$ \\
\hline Holding a glass & $\mathrm{Y}$ & $\mathrm{N}$ & $\mathrm{Y}$ & $\mathrm{N}$ \\
\hline Wrist flexion & $\mathrm{Y}$ & $\mathrm{N}$ & $\mathrm{Y}$ & $\mathrm{N}$ \\
\hline Elbow flexion (in supination) & $\mathrm{Y}$ & $\mathrm{N}$ & $\mathrm{Y}$ & $\mathrm{N}$ \\
\hline Elbow flexion (in pronation) & $\mathrm{Y}$ & $\mathrm{N}$ & $\mathrm{Y}$ & $\mathrm{N}$ \\
\hline Elbow extension & $\mathrm{Y}$ & $\mathrm{N}$ & $\mathrm{Y}$ & $\mathrm{N}$ \\
\hline \multicolumn{5}{|l|}{ Lower limbs: } \\
\hline Toes movements & $\mathrm{Y}$ & $\mathrm{N}$ & $\mathrm{Y}$ & $\mathrm{N}$ \\
\hline Ankle dorsiflexion & $\mathrm{Y}$ & $\mathrm{N}$ & $\mathrm{Y}$ & $\mathrm{N}$ \\
\hline Plantar flexion & $\mathrm{Y}$ & $\mathrm{N}$ & $\mathrm{Y}$ & $\mathrm{N}$ \\
\hline Knee flexion & $\mathrm{Y}$ & $\mathrm{N}$ & $\mathrm{Y}$ & $\mathrm{N}$ \\
\hline Hip flexion & $\mathrm{Y}$ & $\mathrm{N}$ & $\mathrm{Y}$ & $\mathrm{N}$ \\
\hline Maintainance of legs against gravity (Mingazzini test) & $\mathrm{Y}$ & $\mathrm{N}$ & $\mathrm{Y}$ & $\mathrm{N}$ \\
\hline Rising on toes & & $\mathrm{Y}$ & $\mathrm{N}$ & \\
\hline Rising on heels & & $\mathrm{Y}$ & $\mathrm{N}$ & \\
\hline Rising from chair (without any support) & & $\mathrm{Y}$ & $\mathrm{N}$ & \\
\hline Walking alone (without any support) & & $\mathrm{Y}$ & $\mathrm{N}$ & \\
\hline$M=$ number of nos: & $/ 28$ & & & \\
\hline \multicolumn{5}{|l|}{ II Reflexes } \\
\hline Biceps & $\mathrm{Y}$ & $\mathrm{N}$ & $\mathrm{Y}$ & $\mathrm{N}$ \\
\hline Triceps & $\mathrm{Y}$ & $\mathrm{N}$ & $\mathrm{Y}$ & $\mathrm{N}$ \\
\hline Supinator (radial periosteal) & $\mathrm{Y}$ & $\mathrm{N}$ & $\mathrm{Y}$ & $\mathrm{N}$ \\
\hline Pronator & $\mathrm{Y}$ & $\mathrm{N}$ & $\mathrm{Y}$ & $\mathrm{N}$ \\
\hline Knee & $\mathrm{Y}$ & $\mathrm{N}$ & $\mathrm{Y}$ & $\mathrm{N}$ \\
\hline Ankle & $\mathrm{Y}$ & $\mathrm{N}$ & $\mathrm{Y}$ & $\mathrm{N}$ \\
\hline $\mathrm{R}=$ number of nos: & $/ 12$ & & & \\
\hline \multicolumn{5}{|l|}{ III Sensory function } \\
\hline \multicolumn{5}{|l|}{ Abnormal sensations: } \\
\hline \multicolumn{5}{|l|}{ Paraesthesiae (tingling numbness, pins and needles) } \\
\hline In the hand & $\mathrm{Y}$ & $\mathrm{N}$ & $\mathrm{Y}$ & $\mathrm{N}$ \\
\hline Between wrist and elbow & $\mathrm{Y}$ & $\mathrm{N}$ & $\mathrm{Y}$ & $\mathrm{N}$ \\
\hline Above elbow & $\mathrm{Y}$ & $\mathrm{N}$ & $\mathrm{Y}$ & $\mathrm{N}$ \\
\hline In the foot & $\mathrm{Y}$ & $\mathrm{N}$ & $\mathrm{Y}$ & $\mathrm{N}$ \\
\hline
\end{tabular}




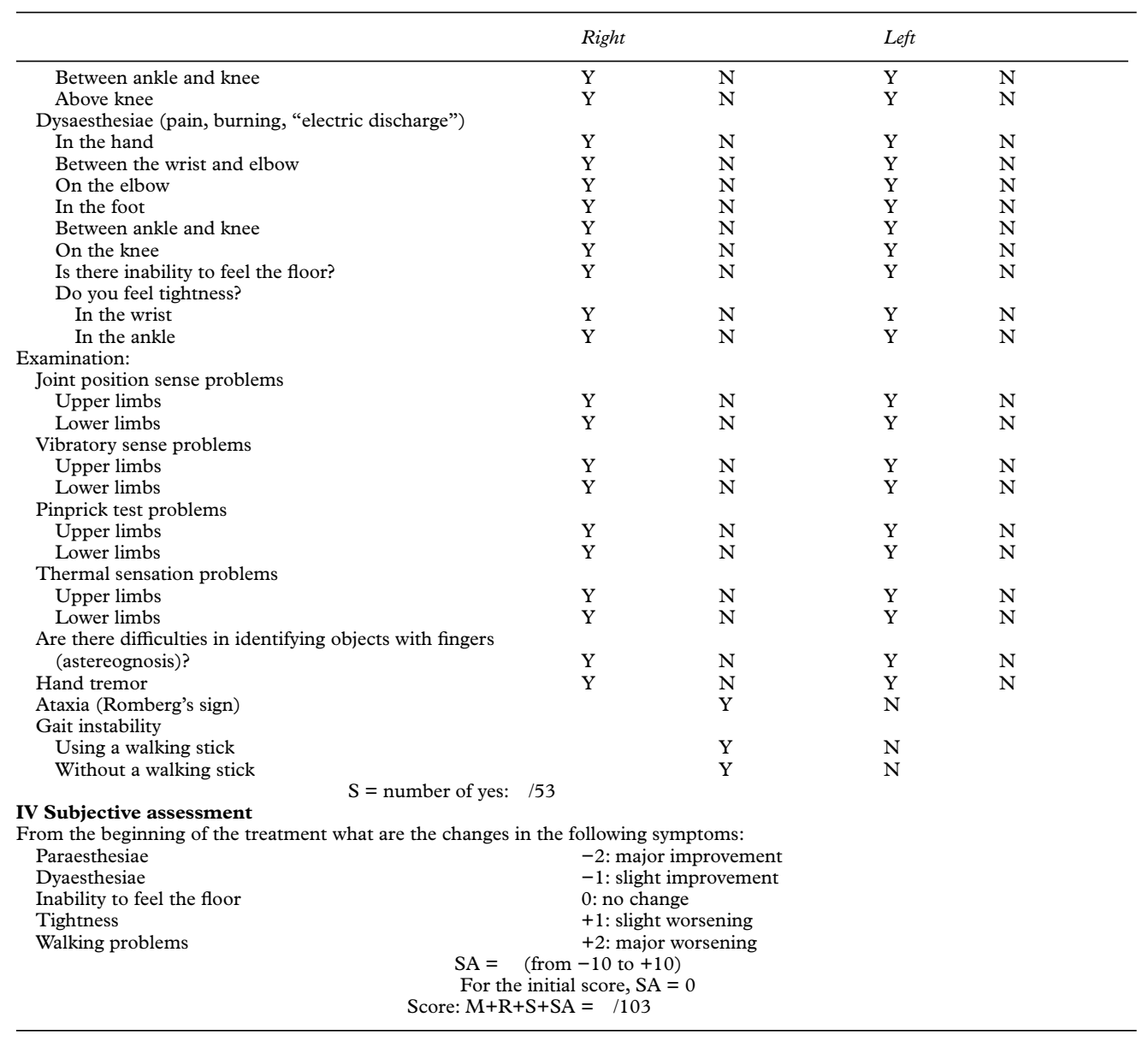

